\title{
Studies on fixed-time ovulation induction in the pig
}

\author{
K.-P. Brüssow' ${ }^{1}$, F. Schneider ${ }^{1}$, W. Kanitz ${ }^{1}$, J. Rátky², J. Kauffold ${ }^{3}$ \\ and $M$. Wähner ${ }^{4}$
}

'FBN Research Institute for the Biology of Farm Animals, D-18196 Dummerstorf, Cermany; ${ }^{2}$ Research Institute for Animal Breeding and Nutrition, $\mathrm{H}-2053$ Herceghalom, Hungary; ${ }^{3} \mathrm{New}$ Bolton Center, School of Veterinary Medicine, University of Pennsylvania, Kennett Square PA 19348, USA; ${ }^{4}$ Anhalt University of Applied Sciences, D-06406 Bernburg, Germany

\begin{abstract}
A technology that allows for manipulating of oestrus and ovulation, and would then also allow for fixed-time insemination, can be of great benefit for swine farms that operate using sow batch management due, at least in part, to savings in labour and the production of large batches of evenly developed pigs. Thanks to the current knowledge on endocrine regulation of follicle development and ovulation, and the availability of numerous reproductively active substances such a technology is now available. It covers procedures for synchronising oestrus based on the use of altrenogest in gilts and of batch-wise weaning in sows, for stimulating follicle development using eCG and for inducing of ovulation using hCG or $\mathrm{LH}$ as well as $\mathrm{GnRH}$ analogues. While the procedures for oestrus synchronisation stand alone, other procedures require additional treatments. If fixed-time insemination is the goal, oestrus needs to be synchronised and follicular development and ovulation induced by the use of $\mathrm{GnRH}$ analogues and hCG with ovulation occurring within 36-42 hrs. It is a general recommendation to inseminate those animals twice, i.e. 24 and 40 hrs after ovulation induction. However, the aforementioned technology requires healthy animals and a solid management and cannot be used to compensate for poor management.
\end{abstract}

\section{Introduction}

More than half a century ago research efforts were made to synchronise the oestrous cycle and ovulation in pigs with the ultimate goal of fixed-time artificial insemination (Al). Tanabe et al. (1949) were the first to treat pigs with equine chorionic gonadotrophin (eCG) and sheep pituitary extracts in order to stimulate follicle development and ovulation. Further studies using methallibure to suppress follicular growth followed by treatment with eCG to stimulate follicle development and human chorionic gonadotrophin (hCG) for inducing ovulation (Polge \& Day $1969)$, and those conducted by Hunter $(1967,1974)$ on ovulation induction as well as on follicle and oocyte development were milestones in the development of procedures to manipulate the oestrus cycle in pigs. Results of these early studies facilitated Eastern-European, particularly East-German research efforts into those procedures starting in 1970 at a time when the farm inventories were growing and there was an increasing need for this kind of biotechnology for management purposes. The general approach was to manipulate female reproductive functions, such as follicular development as well as ovulation and parturition. However, the goal was to 
mimic what occurs physiologically in the female pig. The ultimate goal was to synchronise all reproductive processes with the advantage of periodic and batch-wise $\mathrm{Al}$, parturition as well as weaning, thereby enabling the practise of all-in-all-out and to produce large groups of pig in the same reproductive state with the same health and immunisation status. Indicative of the success made over the years in reproductive biotechnology in 1990, controlled reproduction was used on $86 \%$ of the 1.1 million breeding sows and gilts in East-Germany. It has been learned that research into and the practical use of biotechnological procedures requires understanding of reproductive processes and the availability of appropriate substances (i.e. hormones or hormonally active substances). While those substances are available in general to manipulate almost all key reproductive processes in the female pig, they are not equally available since their use in practice requires national approval. As compared to Europe, hormones or hormonally active substances are still rarely used in the North and South American as well as the Asian swine industry. However, during the last decade due to increased costs for labour, feed and energy resulted in new interest in using those substances that allow for manipulating reproductive processes in the female pig.

\section{Follicle development and ovulation}

Follicular development in gilts and sows has been reviewed in detail elsewhere (Prunier \& Quesnel 2000, Schwartz et al. 2008). In gilts the follicle cohort destined to ovulate is stimulated by increased post-ovulatory $\mathrm{FSH}$, but under the influence of the high luteal progesterone (P4) concentration during dioestrus follicles do not grow to ovulatory size. Only after luteolysis when P4 is low and thus does not negatively feedback on gonadotrophin synthesis, follicles finally grow from $4 \mathrm{~mm}$ to ovulatory size within 4-6 days. However, there is a well-defined balance between stimulatory (e.g. LH and FSH) and inhibitory (e.g. P4 and inhibin) factors that favours pre-ovulatory follicle development. As has been shown after gonadotrophin deprivation, $\mathrm{FSH}$ is necessary to support follicle development beyond $2-3 \mathrm{~mm}$ and $\mathrm{LH}$ beyond $4 \mathrm{~mm}$ (Driancourt et al. 1995). Once the follicles reach a larger preovulatory stage FSH declines (Guthrie \& Bolt 1990) and LH pulse secretion changes from luteal (high amplitude - low frequency) to follicular patterns (low amplitude - high frequency). Final stage of follicular development is associated with decreased $\mathrm{FSH}$ and increased $\mathrm{LH}$ receptor expression along with increased production of oestradiol, as well as increased fluid accumulation within the follicular cavity. Increased preovulatory oestradiol finally elicits the $\mathrm{GnRH}$-mediated $\mathrm{LH}$ release from the pituitary, thereby initiating ovulation and the release of a mature oocyte.

Sows commonly have a lactational anoestrus. During lactation and before weaning, follicles exhibit a wave-like pattern of growth, and emerge from a cohort of 20-30 follicles of $2 \mathrm{~mm}$ that grow to not larger than $5 \mathrm{~mm}$ (Lucy et al. 2001). This is because suckling inhibits secretion of $\mathrm{GnRH}$ and subsequently $\mathrm{LH}$ due to a concerted action of prolactin, oxytocin and endogenous opioid peptides that prevent final growth of these follicles to reach ovulatory size before weaning (Varley \& Foxcroft 1990). Once the piglets are weaned, follicles start to grow to 7-8 $\mathrm{mm}$ before ovulation. Initially FSH increases and then decreases at weaning. Basal $\mathrm{LH}$ and $\mathrm{LH}$ pulse frequency increases; these are key regulators of post-weaning follicle development which affect the weaning to oestrus interval (van de Brand et al. 2000). Furthermore, adrenal hormones and nutritional mediators such as glucose, insulin and free fatty acids, as well as endogenous opioids and leptin have been shown to have an influence on post-weaning follicle development and ovulation. In conclusion, follicle development including the final ovulatory follicle growth and maturation, as well as ovulation itself, requires fine-tuned hormonal events. Understanding these mechanisms is necessary in any attempt to manipulate the reproductive process in female swine. 


\section{Manipulation of follicle development and ovulation}

\section{Synchronisation of oestrus}

In a batch farrowing system, oestrus in sows is naturally synchronised by weaning. Oestrous cycles of gilts need to be synchronised when they are introduced into such systems. For this purpose, protocols based on either suppression of follicle development and/or mimicking the luteal phase are available (reviewed by Estill 2000). Progesterone and its synthetic derivates did not prove fully effective for oestrus synchronisation. In contrast, non-steroidal substances such as methallibure (Aimax, $\mathrm{ICl} 33828$, Suisynchron ${ }^{-}$) have been shown to yield good results, but were banned by US and European countries before being commercially available for the swine industry because of their teratogenic effects. In East-Germany, zinc-methallibure (Siusynchron ${ }^{\circledR}$ ) was successfully used in hundreds of thousands of gilts between 1973 and 1989, but was then also banned and replaced by allyltrenbolone (Hühn et al. 1996). At present, allyltrenbolone (altrenogest, as Regumate ${ }^{\odot}$ in Europe and Matrix ${ }^{\odot}$ in North America) is the only licensed substance with progestagene type effects to be used in female pigs in Europe and in North America. If it is given orally and fed in a dose of 15 to $20 \mathrm{mg} /$ day/gilt over a period of 14 to 18 days, it has been proven effective at suppressing follicle development. Recommendations on the daily dose of altrenogest and the duration of administration differ between countries. Production sites in France and also some in Germany prefer feeding $20 \mathrm{mg} /$ day/gilt for 18 days (Martinat-Botte et al. 1990). Other sites in Germany use feeding altrenogest in doses of $16-20 \mathrm{mg} /$ day/gilt over 15 days and achieved good fertility results (Hühn et al. 1996). For North America, the general recommendation is $15 \mathrm{mg} /$ day/gilt for 14 days. Feeding of altrenogest for a shorter period is possible, if the stage of oestrous cycle is known at first administration (Kirkwood 1999). Gilts usually show oestrus within 5 to 7 days after altrenogest withdrawal (Martinat-Botte et al. 1990, Hühn et al. 1996). Other approaches have been to include progesterone or $\mathrm{GnRH}$ agonists in a slow release device during a defined time, in conjunction with hCG or oestrogen to extend the lifespan of the corpora lutea, and the 'breed-and-abort' procedure using PGF ${ }_{2 \alpha}$. However, all of the aforementioned procedures except those based on the use of altrenogest are not currently used in the swine industry.

\section{Stimulation of follicular development}

Though synchronisation of oestrus is possible, with weaning group of sows or treatment with altrenogest in gilts, the onsets of oestrus can however still spread over a week. This is due, at least in part, to insufficient follicle development. Gonadotrophins may then be used after weaning or after altrenogest in order to stimulate this follicle development and to achieve a better synchronisation effect.

Equine CG, which is a glycoprotein similar to equine pituitary $\mathrm{LH}$, has been proven to have superior effects on follicle development in pigs. This gonadotrophin exhibits both LH- and FSH-like activities (Farmer \& Papkoff 1979) with a FSH/LH activity ratio that differs between 0.14 to 0.31 as estimated by bioassays conducted in rats and mice (Bergfeld \& Haring 1983). A different ratio of $\mathrm{FSH}$ versus $\mathrm{LH}$ activity may account for variations in the ovarian response seen in pigs after use of different eCG batches (Bergfeld \& Haring 1983, Ciller et al. 2008), and should be considered when analysing the effectiveness of different treatment protocols that are based on eCG. As evident from numerous East-German experiments, 800 to 1,000 IU of eCG are most effective at stimulating follicle development in gilts and 600 to $1,000 \mathrm{IU}$ eCG in sows. However, within- and between-farm differences occur, as indicated by variations in the ovarian response of sows that received the same eCG treatment but were located at different 
farms. This observation needs to be considered when determining an optimal dose of eCG (Bergfeld et al. 1984). It is recommended to test different eCG dosages first and then pick the one that yielded the optimum fertility. Besides the dose, the time when treatment occurs with eCG affects follicle development. For instance, the application of eCG one day after, or the last day of methallibure feeding in gilts (Polge et al. 1968) or 48 versus $24 \mathrm{hrs}$ after methallibure (Brüssow \& Bergfeld 1984) was associated with an increased number of stimulated follicles and also with a lower dosages of ECG needed for stimulation. Whenever a protocol includes the use of eCG it needs to be evaluated, for example by evaluating the ovary at slaughter, laparotomy, laparoscopy and ultrasound.

Besides pure eCG, different combinations of the gonadotrophins eCG and hCG have been used for stimulation of follicle development and oestrus in gilts and sows (Estienne et al. 2001, Knox et al. 2001). However, using such combinations there is evidently the risk of inducing ovarian cysts and/or of premature luteinization of follicles. The latter is assumed due to the higher LH activity of those combinations compared to pure eCG, most likely as the result of the extra hCG (Bergfeld et al. 1982). Increasing eCG and hCG in a combination from 400 to $700 \mathrm{IU}$ and from 200 to $350 \mathrm{IU}$, respectively, was associated with an increased number of gilts with cystic ovarian degeneration (36\% versus $88 \%$ ) and a decrease in the pregnancy rate $(50 \%$ versus $65 \%$ ). In contrast, when gilts were treated with 1,000 IU eCG, only $4 \%$ of them developed ovarian cysts (Schlegel et al. 1978). Moreover, if 1,000 IU eCG was given to primi- and multiparous sows $24 \mathrm{hrs}$ after weaning and compared to $400 \mathrm{IU}$ eCG/200 IU hCG (Suigonan ${ }^{\circledR}$, Intervet, Unterschleissheim, Germany), the pregnancy rates, litter sizes and piglet indices were all higher in sows that received eCG only (Barbe et al. 1997). Taken together the majority of the studies that were conducted in former East-Germany suggest that pure eCG stimulates follicle development with better fertility results than do combinations of eCG and hCG. This is certainly the reason why standardized, lyophilized eCG preparation (e.g. Pregmagon ${ }^{\oplus}$; IDT Dessau, Germany) is given preference in the German pig industry for the purpose of stimulating follicle development in pigs. However, in the United States, a drug that combines $400 \mathrm{IU}$ eCG and 200 IE hCG, i.e. PG 600 (Intervet Canada, Guelph, Ontario, Canada) is the preferred medication, and has been shown being effective for a multitude of reproductive purposes (Kirkwood 1999).

Synthetically produced $\mathrm{GnRH}$ agonists have been used to stimulate follicle development in pigs, and are considered as an alternative to eCG. Recently, a synthetic analogue of lamprey GnRH-III (Peforelin; Maprelin ${ }^{\circ}$ XP10, Veyx-Pharma, Schwarzenborn, Germany), was shown to exhibit selective FSH releasing activity in barrows (Kauffold et al. 2005), has been used in primi- and multiparous sows to stimulate follicle development and oestrus, and yielded similar fertility results than eCG (Engl et al. 2006). However, a general recommendation for its broad use would greatly benefit from further endocrine studies and supportive field results.

\section{Induction of ovulation}

Though the onset of oestrus and to some extend also ovulation can be synchronised in both gilts and sows by using eCG, the time when ovulation occurs can be still extremely variable. If fixedtime insemination is the goal, ovulation needs to be induced, either by using gonadotrophins with predominately $\mathrm{LH}$ activity such as hCG or by using GnRH analogues. Human CG (Hunter 1967) or equivalent substances such as pituitary extracts (Tanabe et al. 1949), aiming to mimic the endogenous pre-ovulatory LH-peak, were effective in gilts at inducing ovulation which occurred at approximately $40-42 \mathrm{hrs}$ after treatment. If animals are treated with eCG to stimulate follicle development and then followed by hCG treatment to induce ovulation, the 
interval between both treatments is however crucial to the ovulation-inducing effect of hCG. Considering that hCG should be given as close as possible to the time when the endogenous $\mathrm{LH}$ peak occurs in order to induce ovulation. Indeed, when this interval has been set at 78-80 hrs after eCG and the responses compared to non-treated controls, treated animals ovulated more uniformly, with ovulations occurring 42-53 hrs after hCG, whereas no control animal ovulate during this time period (Bergfeld et al. 1976).

Porcine LH (pLH, Lutropin-V, Bioniche Animal Health, Belleville, Canada) has been shown to be as effective as hCG at synchronising ovulation in weaned sows (Cassar et al. 2005, Bennett-Steward et al. 2008). If eCG was given the day of weaning and pLH 80 hrs later, sows ovulated between 34-42 hrs post pLH (Cassar et al. 2005).

After $\mathrm{GnRH}$, a decapeptide, was discovered and its structure known, the pharmaceutical industry started to synthesize $\mathrm{GnRH}$ and thus made it available for use in swine industry. In contrast to hCG, GnRH acts at the pituitary level and stimulates the release of endogenous $\mathrm{LH}$, thereby approximating what is a more "biologically normal" event than does hCG. Once more the East-German pig industry took the initiative in the development of one of the first GnRH analogues, i.e. Gn-RH vet "Berlin-Chemie" for use in swine in the late 70s. Brüssow \& Bergfeld (1979) and Bergfeld \& Brüssow (1979) performed intensive studies on the effect of different doses of this $\mathrm{GnRH}$ analogue alone or in combination with hCG on ovulation and observed that, $900 \mu \mathrm{g}$ of this $\mathrm{GnRH}$ analogue alone or different combinations of GnRH/hCG $(100-300 \mu \mathrm{g}$ $\mathrm{GnRH/100-300} \mathrm{IU} \mathrm{hCG)} \mathrm{stimulate} \mathrm{ovulation} \mathrm{similar} \mathrm{to} \mathrm{what} \mathrm{was} \mathrm{achieved} \mathrm{with} \mathrm{only} \mathrm{hCG.}$

Later, another GnRH agonist (D-Phe ${ }^{6}-\mathrm{LHRH}_{\text {, Gonavet }}{ }^{\circ}$, Berlin-Chemie, Berlin, Germany) was demonstrated to be even more effective at synchronising ovulation in swine than $\mathrm{Gn}-\mathrm{RH}$ vet "Berlin-Chemie". As observed by repeated laparoscopy (Brüssow et al. 1990), in gilts treated with $50 \mu \mathrm{g}$ D-Phe ${ }^{6}$-LHRH started ovulating $35.5 \pm 2.7 \mathrm{hrs}$ after treatment and finished ovulation on average $5.9 \pm 1.7 \mathrm{hrs}$ later. However, animals varied in their response to D-Phe ${ }^{6}-\mathrm{LHRH}$, with variations being related to the interval between the $\mathrm{GnRH}$ injection and the $\mathrm{LH}$ peak, the maximum of the LH peak and the overall time needed for ovulation (Table 1). Typical LH secretion patterns observed in gilts after GnRH (Gonavet ${ }^{(\bullet)}$ treatment are shown in Fig. 1.

Table t. Effects of $50 \mu \mathrm{g}$ D-Phe ${ }^{6}$-LHRH (Gonavet ${ }^{9}$ ) on LH and ovulation in gilts (from Brüssow et al. 1994)

\begin{tabular}{lccc}
\hline Criteria & $\begin{array}{c}\text { Early* responder } \\
(\mathrm{n}=6)\end{array}$ & $\begin{array}{c}\text { Medium* } \\
\text { responder } \\
(\mathrm{n}-6)\end{array}$ & $\begin{array}{c}\text { Late* responder } \\
\text { (n }-4)\end{array}$ \\
\hline GnRH - LH surge (hrs) & $2.2 \pm 0.4^{\mathrm{a}}$ & $5.0 \pm 1.0^{\mathrm{b}}$ & $9.0 \pm 1.0^{\mathrm{c}}$ \\
LH maximum (ng/ml) & $19.6 \pm 9.8^{\mathrm{a}}$ & $7.3 \pm 3.2^{\mathrm{b}}$ & $3.8^{\mathrm{b}} \pm 0.8^{\mathrm{c}}$ \\
GnRH - commencement of ovulation (hrs) & $35.6 \pm 2.4^{\mathrm{a}}$ & $34.6 \pm 2.5^{\mathrm{a}}$ & $39.6 \pm 1.5^{\mathrm{b}}$ \\
GnRH - completion of ovulation (hrs) & $39.0 \pm 1.8^{\mathrm{a}}$ & $37.2 \pm 2.5^{\mathrm{a}}$ & $42.0 \pm 1.5^{\mathrm{b}}$ \\
LH peak - commencement of ovulation (hrs) & $33.4 \pm 2.5$ & $29.4 \pm 3.9$ & $30.6 \pm 0.6$ \\
LH peak - completion of ovulation (hrs) & $35.8 \pm 1.7^{\mathrm{a}}$ & $32.2 \pm 2.7^{\mathrm{b}}$ & $35.5 \pm 3.8$ \\
Duration of ovulation (hrs) & $3.6 \pm 2.3$ & $2.8 \pm 1.7$ & $2.4 \pm 0.2$ \\
\hline
\end{tabular}

का $\mathrm{p}<0.05$,

* Animals were classified as early, medium and late responder according to their LH peak as response to GnRH.

Field trials involving a total of 2,744 gilts that were all injected with $50 \mu \mathrm{g}$ D-Phe -LHRH $^{-\mathrm{L}}$ (Gonave ${ }^{(\oplus)}$ ) 78-80 hrs after 1,000 IU eCG and artificially inseminated twice at fixed times, i.e. 24 and $40 \mathrm{hrs}$ after $\mathrm{GnRH}$, demonstrated that D-Phe ${ }^{6}-\mathrm{LHRH}$ yields superior fertility results than if ovulation was induced with hCG. A similar observation has been made with 71,600 sows that were treated with $50 \mu \mathrm{g}$ D-Phe - $^{-\mathrm{LHRH}}$ compared to $300 \mu \mathrm{g} \mathrm{GnRH/300} \mathrm{IU} \mathrm{hCG} \mathrm{combination}$ 55-58 hrs after eCG and artificialty inseminated twice at 24 and $42 \mathrm{hrs}$ after GnRH (Brüssow 
(A)

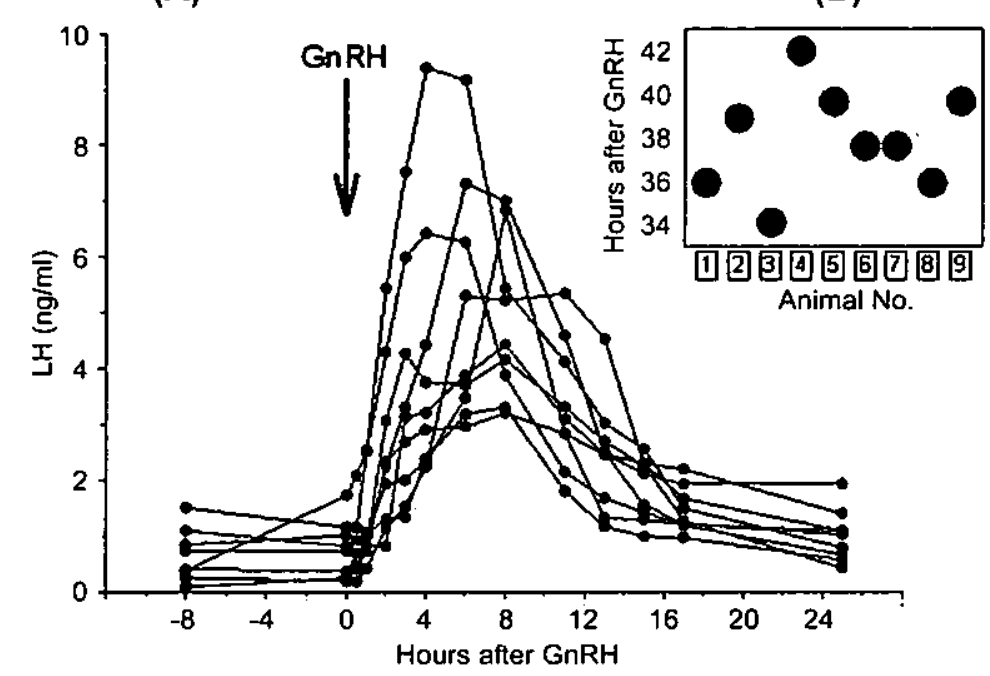

(B)

Fig. $1 \mathrm{LH}$ response $(\mathrm{A})$ and time of ovulation $(\mathrm{B})$ in gilts $(n-9)$ treated with $50 \mu \mathrm{g}$ D-Phe ${ }^{6}$-LHRH (Gonavet ${ }^{\circ}$ ) $80 \mathrm{hrs}$ after eCG

et al. 1996). Other GnRH analogues that have been tested for ovulation induction in swine are buserelin (Möller-Holtkamp et al. 1995), goserelin (Brüssow et al. 2007) and triptorelin (Taibl et al. 2008). All of them are effective at stimulating pre-ovulatory $\mathrm{LH}$ secretion in both gilts and sows. Currently however, D-Phe ${ }^{6}$-LHRH is still the only $\mathrm{CnRH}$ analogue that has been licensed for use in swine in a number of European countries including Germany. The intravaginal application of $\mathrm{GnRH}$ containing gel (Baer \& Bilkei 2004, Taibl et al. 2008) has been tested for the purpose of ovulation induction, but did not reach a stage beyond research. Another neuronal peptide, kisspeptin, which is a product of the KISS1 gene (Kotani et al. 2001) and synthesised as a preprohormone, has gained increasing interest lately since it is involved in the regulation of GnRH release, and if given to female pigs has been shown to stimulate LH release in a dose dependent manner (Lents et al. 2008). Though kisspeptin is thus a promising candidate to induce ovulation in pigs the question of whether or not it will ever be used in the pig industry for this purpose as part of a fixed-time insemination protocol needs further investigation.

\section{Protocols for fixed-time ovulation and insemination in practice}

The German pig industry has a long and strong history of using biotechnology in pig reproduction. Supported by continuing research efforts, the industry has many years experience with this type of technology (Hühn et al. 1996, Brüssow et al. 1996), and has thus been able to recommend different protocols that can be used for oestrus synchronisation and fixed-time insemination in pigs (Table 2). However, other approaches are also possible such as the one reported recently and performed with 3,000 sows on commercial farms in Canada (Cassar et al. 2005, Bennett-Steward et al. 2008). In these studies, sows were injected with $600 \mathrm{IU}$ eCG at the day of weaning and were given $5 \mathrm{mg} \mathrm{pLH} 80 \mathrm{hrs}$ later. They were then inseminated at fixed-times 36 and $44 \mathrm{hrs}$ after pLH. Compared to untreated controls, the farrowing rate of treated sows was significantly increased ( $86 \%$ versus $69 \%$ ). 
Table 2. Treatment protocols for ovulation induction and fixed-time insemination in gilts and sows as recommended for use in practice based on experience from the East-German swine industry

\begin{tabular}{|c|c|c|}
\hline Method & Gilits & Sows \\
\hline \multirow[t]{2}{*}{$\begin{array}{l}\text { Synchronisation } \\
\text { of oestrous cycle }\end{array}$} & $\begin{array}{l}18 \text { days oral application of altrenogest }(20 \\
\mathrm{mg} / \text { gilt/ day) }(08: 00 \mathrm{~h})\end{array}$ & Lactation until weaning \\
\hline & $\begin{array}{l}15 \text { days oral application of altrenogest ( } 16 \\
\mathrm{mg} / \text { gilt/day) }(08: 00 \mathrm{~h})\end{array}$ & \\
\hline \multirow{2}{*}{$\begin{array}{l}\text { Stimulation } \\
\text { of follicle } \\
\text { development }\end{array}$} & $\begin{array}{l}800-1,000 \mathrm{IU} \text { eCC } 24 \mathrm{hrs} \text { after last } \\
\text { altrenogest }(08: 00 \mathrm{~h})\end{array}$ & $\begin{array}{l}\text { Primiparous sows } 1,000 \mathrm{IU} \text { eCG } 24 \text { hrs after } \\
\text { weaning }(08: 00 \mathrm{~h})\end{array}$ \\
\hline & & $\begin{array}{l}\text { Multiparous sows } \\
600-800 \mathrm{IU} \text { eCG } 24 \mathrm{hrs} \text { after weaning (08:00 h) }\end{array}$ \\
\hline \multirow[t]{3}{*}{$\begin{array}{l}\text { Induction of } \\
\text { ovulation }\end{array}$} & $\begin{array}{l}\text { GnRH* or hCG**78-80 hrs after eCG } \\
(14: 00-16: 00 \mathrm{~h})\end{array}$ & $\begin{array}{l}\text { Lactation }>4 \text { weeks } \\
\text { GnRH* or hCG** } 56-58 \text { hrs after eCG } \\
(16: 00-18: 00 \mathrm{~h})\end{array}$ \\
\hline & & $\begin{array}{l}\text { Lactation } 4 \text { weeks } \\
\text { GnRH* or hCG** } 72 \mathrm{~h} \text { after eCG }(16: 00 \mathrm{~h})^{* * *}\end{array}$ \\
\hline & & $\begin{array}{l}\text { Lactation } 3 \text { weeks } \\
\text { GnRH* or hCG** } 78-80 \text { hrs after eCG } \\
(14: 00-16: 00 \mathrm{~h})\end{array}$ \\
\hline 1 st $\mathrm{Al}$ & 24-26 hrs after $\mathrm{GnRH}^{*}$ or hCG** & 24-26 hrs after GnRH* or hCG** \\
\hline 2nd Al & 38-40 hrs after $\mathrm{GnRH} H^{*}$ or hCG** & $40-42$ hrs after $\mathrm{GnRH} \mathrm{RH}^{*}$ or hCG ${ }^{* *}$ \\
\hline
\end{tabular}

* e.g $50 \mu \mathrm{g}$ Gonavet ${ }^{\circ}, * * 500 \mathrm{IU} \mathrm{hCG},{ }^{* * *}$ weaning one day earlier in the afternoon

\section{Conclusions}

A technology is currently available that allows for manipulation of almost all key reproductive processes in the female pig including oestrus and ovulation, making fixed-time insemination possible. Batch farrowing systems may profit from using this technology due, at least in part, to savings on labour and production of large batches of uniformly developed and healthy pigs. This technology does however not allow for compensation of health problems and/or mismanagement. Understanding of reproductive processes and the availability of hormonally active drugs are essential requirements when deciding to use this technology. However, several factors related to the farms themselves, as well as to the drugs may influence the effectiveness and outcome of this technology. It is thus recommended to adapt this technology to each individual farm.

\section{References}

Barbe C, Wähner M \& Schnurrbusch U 1997 Influence of PMSG and PMSG/hCG-combinations on fertility of weaned sows 2. Effect of different methods of cycle stimulation after weaning on fertility Archiv für Tierzucht 40 567-580.

Baer C \& Bilkei G 2004 The effect of intravaginal applied GnRH-agonist on the time of ovulation and subsequent reproductive performance of weaned multiparous sows. Reproduction in Domestic Animals 39 293-297.

Bennet-Steward K, Aramini J, Pelland C \& Friendship R 2008 Equine chorionic gonadotrophin and porcine luteinizing hormone to shorten and synchronize the wean-to-breed interval among parity-one and paritytwo sows. Journal of Swine Health and Production 16 182-187.
Bergfeld J, Falge R, Hühn R \& Kauffold P 1976 Experimental biological engineering to synchronise ovulation in gilts III Onset of ovulation, ovarian findings and fertilization following methallibure, 750 IU PMS with and without $500 \mathrm{IU}$ hCG at different times of treatment. Archiv für experimentelle Veterinärmedizin 30 471-480.

Bergfeld I \& Brüssow KP 1979 Preclinical studies into synchronisation of ovulation in gilts following treatment with Suisynchron PMSG and hCG/Gn-RH combination. Monatshefte für Veterinärmedizin 34 613-615.

Bergfeld J, Brüssow KP, Tiemann U \& Raasch ML 1982 Orientation studies into selection of parameters for assessment of mixed gonadotrophic preparations for their biological effects on female fattening pigs. Archiv 
für experimentelle Veterinärmedizin 36 25-34.

Bergfeld J \& Haring E 1983 Determination of gonadotrophic valence of preparations made of serum of pregnant mares (PMSG) III Biological determination of activity of "PMSG substandard Dessau" in bioassays for folliclestimulating hormone (FSH) and luteinizing hormone (LH). Archiv für experimentelle Veterinärmedizin 37 801-806.

Bergfeld J, George G \& Brüssow KP 1984 Studies into dynamics and potency of ovulation in groups of sows on several farms following differentiated treatment to stimulate ovulation. Archiv für experimentelle Veterinärmedizin 38 849-856.

Brüssow KP \& Bergfeld ) 1979 Preliminary studies into Gn-RH and its use to release ovulation in prepuberal gilts and those with synchronised oestrus. Monatshefte für Veterinärmedizin 34611-613.

Brüssow KP \& Bergfeld J 1984 Studies into time shifting of ovulations in gilts by modification of injection dates in the context of synchronised ovulation. Archiv für Experimentelle Veterinärmedizin 38 840-848.

Brüssow KP, Rátky J, Kanitz E \& Becker F 1990 The relationship between the surge of $L H$ induced by exogenous Gn-RH and the duration of ovulation in gilts. Reproduction in Domestic Animals 25 255-260.

Brüssow KP, Kanitz E \& Rátky J 1994 The dynamic of plasma luteinizing hormone surge and its relationships to the time of ovulation in gilts following exogenous GnRH. Archiv für Tierzucht 37 55-63.

Brüssow KP, Jöchle $W$ and Hühn U 1996 Control of ovulation with a GnRH analog in gilts and sows. Theriogenology 96 925-934.

Brüssow KP, Schneider F, Tuchscherer A, Rátky J, Kraeling RR \& Kanitz W 2007 Luteinizing hormone release after administration of the gonadotropinreleasing hormone agonist Fertilan (goserelin) for synchronization of ovulation in pigs. Journal of Animal Science 85 129-137.

Cassar C, Kirkwood RN, Poljak Z, Bennett-Steward K \& Friendship RM 2005 Effect of single or double insemination on fertility of sows bred at an induced estrus and ovulation. Journal of Swine Health and Production 13 254-258.

Ciller UA, Ciller IM \& McFarlane JR 2008 Equine chorionic gonadotrophin isoform composition in commercial products compared with isoform composition in pregnant mare plasma. Reproduction Fertility \& Development Supplement 2077.

Driancourt MA, Locatelli A \& Prunier A 1995 Effects of gonadotrophin deprivation on follicular growth in gilts. Reproduction Nutrition and Development 35 663-673.

Engl S, Kauffold J, Sobiraj A \& Zaremba W 2006 Investigations into the suitability of a $\mathrm{GnRH}$-variant for estrus induction in pluriparous sows. Reproduction in Domestic Animals 41 Supplement 133.

Estienne MJ, Harper AF, Horsley BR, Estienne CE \& Knight JW 2001 Effects of PG600 on the onset of estrus and ovulation rate in gilts treated with Regumate.
Journal of Animal Science 79 2757-2761.

Estill CT 2000 Current concepts in estrus synchronization in swine. Journal of Animal Science 77 1-9.

Farmer SW \& Papkoff HH 1979 Immunochemical studies with pregnant mare serum gonadotropins. Biology of Reproduction 21 425-431.

Guthrie HD \& Bolt DJ 1990 Changes in plasma follicle stimulating hormone, luteinizing hormone, estrogen and progesterone during growth of ovulatory follicles in the pig. Domestic Animal Endocrinology 7 83-91.

Hühn U, Jöchle W \& Brüssow KP 1996 Techniques developed for the control of estrus, ovulation and parturition in the East German pig industry: A review. Theriogenology 46 911-924.

Hunter RHF 1967 The porcine ovulation after injection of human chorionic gonadotrophin. The Veterinary Record 81 21-23.

Hunter RHF 1974 Chronological and cytological details of fertilization and early embryonic development in the domestic pig, Sus scrofa. Anatomical Record 178 169-186.

Kauffold J, Schneider F, Zaremba W \& Brüssow KP 2005 Lamprey GnRH-III stimulates FSH secretion in barrows. Reproduction in Domestic Animals $\mathbf{4 0}$ 475-479.

Kirkwood RN 1999 Pharmacological intervention in swine reproduction. Swine Health and Production 7 29-35.

Knox RV, Rodriguez-Zas SL, Miller GM, Willenburg KL \& Robb JA 2001 Administration of PG 600 to sows at weaning and the time of ovulation as determined by transrectal ultrasound. Journal of Animal Science 79 796-802.

Kotani M, Detheux M, Vandenbogaerde A, Communi D, Vanderwinden JM, Le Poul E, Brezillon S, Tyldesley R, Suarez-Huerta N, Vandeput F, Blanpain C, Schiffmann SN, Vassart G \& Parmentier M 2001 The metastasis suppressor gene KiSS-1 encodes kisspeptins, the natural ligands of the orphan $G$ protein-coupled receptor GPR54. Journal of Biological Chemistry 276 34631-34636.

Lents CL, Heidorn NL, Barb CR \& Ford || 2008 Central and peripheral administration of kisspeptin activates gonadotropin but not somatotropin secretion in prepubertal gilts. Reproduction 135 879-887.

Lucy MC, Liu J, Boyd CK \& Bracken C) 2001 Ovarian follicular growth in sows. Reproduction Supplement $5831-45$.

Martinat-Botte F, Bariteau F, Forgerit Y, Macar C, Moreau A, Terqui M \& Signoret JP 1990 Oestrus control in gilts II synchronization of oestrus with the progestagen altrenogest (Regumate) effect on fertility and litter size. Animal Reproduction Science 22 227-233.

Möller-Holtkamp P, Stickan F, Parvizi N \& Elsaesser F 1995 Release of $\mathrm{LH}$ in pigs after administration of the GnRH agonist buserelin in comparison to D-Phe6-LHRH. Reproduction in Domestic Animals 30 21-24.

Polge C, Day BN, \& Groves TW 1968 Synchronisation 
of ovulation and artificial insemination in pigs. The Veterinary Record 83 136-142.

Polge C \&.Day BN 1969 Induction of estrus and ovulation in swine during pituitary suppression with methallibure. Journal of Animal Science 69 73-75.

Prunier A \& Quesnel H 2000 Nutritional influences on hormonal control of reproduction in female pigs. Livestock Production Science 63 1-16.

Schlegel W, Wähner M \& Stenzel S 1978 Different combinations of PMS and hCG - use for cycle stimulation in synchronized ovulation of gilts and effects on results of pregnancy. Monatshefte für Veterinärmedizin 33 663-664.

Schwartz T, Kopyra M \& Nowicki M 2008 Physiological mechanisms of ovarian follicular growth in pigs - a review. Acta Veterinaria Hungarica 56 369-378.

Taibl JN, Breen SM, Webel SK \& Knox RV 2008 Induction of ovulation using a GnRH agonist for use with fixed time Al in weaned sows. Theriogenology 701400
Tanabe TY, Warnick AC, Casida LE \& Grummer RH 1949 The effect of gonadotrophins administerd to sows and gilts during different stages of the estrual cycle. Journal of Animal Science 8 550-557.

van den Brand H, Dielemann SJ, Soede NM \& Kemp B 2000 Dietary energy source at two feeding levels during lactation in primiparous sows: I Effect on glucose, insulin, and luteinizing hormone and on follicle development, weaning-to-estrus interval, and ovulation rate. Journal of Animal Science 78 396-404.

Varley MA \& Foxcroft GR 1990 Endocrinology of the lactating and weaned sow fournal of Reproduction and Fertility Supplement 40 47-61. 